\title{
Micro-heterogeneity of malaria transmission in the Peruvian Amazon: a baseline assessment underlying a population-based cohort study
}

\author{
Angel Rosas-Aguirre ${ }^{1,2}$, Mitchel Guzman-Guzman ${ }^{3}$, Dionicia Gamboa ${ }^{1,3,4}$, Raul Chuquiyauri ${ }^{1,6}$, \\ Roberson Ramirez ${ }^{3}$, Paulo Manrique ${ }^{3}$, Gabriel Carrasco-Escobar ${ }^{3,5}$, Carmen Puemape ${ }^{3}$, \\ Alejandro Llanos-Cuentas ${ }^{1,5}$ and Joseph M. Vinetz ${ }^{1,3,4,6^{*}}$
}

\begin{abstract}
Background: Understanding the dynamics of malaria transmission in diverse endemic settings is key for designing and implementing locally adapted and sustainable control and elimination strategies. A parasitological and epidemiological survey was conducted in September-October 2012, as a baseline underlying a 3-year population-based longitudinal cohort study. The aim was to characterize malaria transmission patterns in two contrasting ecological rural sites in the Peruvian Amazon, Lupuna (LUP), a riverine environment, and Cahuide (CAH), associated with roadlinked deforestation.

Methods: After a full population census, 1941 individuals 3 years and older (829 in LUP, 1112 in CAH) were interviewed, clinically examined and had a blood sample taken for the detection of malaria parasites by microscopy and PCR. Species-specific parasite prevalence was estimated overall and by site. Multivariate logistic regression models assessed risk factors for parasite infection by PCR, while SaTScan detected spatial clusters of PCR-positive individuals within each site. In addition, data from routine malaria surveillance in the period 2009-2012 were obtained.

Results: Parasite prevalence by PCR was higher in CAH than in LUP for Plasmodium vivax (6.2\% vs. 3.9\%) and for Plasmodium falciparum (2.6\% vs. 1.2\%). Among PCR-confirmed infections, asymptomatic (Asy) parasite carriers were always more common than symptomatic (Sy) infections for P. vivax (Asy/Sy ratio: 2/1 in LUP and 3.7/1 in CAH) and for P. falciparum (Asy/Sy ratio: 1.3/1 in LUP and 4/1 in CAH). Sub-patent (Spat) infections also predominated over patent (Pat) infections for both species: P. vivax (Spat/Pat ratio: 2.8/1 in LUP and 3.7/1 in CAH) and P. falciparum malaria (Spat/Pat ratio: 1.9/1 in LUP and 26/0 in CAH). For CAH, age, gender and living in a household without electricity were significantly associated with P. vivax infection, while only age and living in a household with electricity was associated with $P$. falciparum infection. For LUP, only household overcrowding was associated with $P$. falciparum infection. The spatial analysis only identified well-defined clusters of P. vivax and P. falciparum infected individuals in CAH. Reported malaria incidence indicated that malaria transmission has long occurred in LUP with primarily seasonal patterns, and confirmed a malaria outbreak in CAH since May 2012.
\end{abstract}

\footnotetext{
*Correspondence: jvinetz@ucsd.edu

${ }^{6}$ Division of Infectious Diseases, Department of Medicine, University

of California San Diego School of Medicine, 9500 Gilman Drive MC0760,

Biomedical Research Facility-2, Room 4A16, La Jolla, California, CA 92093,

USA

Full list of author information is available at the end of the article
} provided you give appropriate credit to the original author(s) and the source, provide a link to the Creative Commons license, and indicate if changes were made. The Creative Commons Public Domain Dedication waiver (http://creativecommons.org/ publicdomain/zero/1.0/) applies to the data made available in this article, unless otherwise stated. 
Conclusions: This parasitological and epidemiological baseline assessment demonstrates that malaria transmission and parasite prevalence is heterogeneous in the Peruvian Amazon, and influenced by local socio-demographics and ecological contexts. Riverine and road construction/deforestation contexts must be taken into account in order to carry out effective anti-malaria control and elimination efforts.

Keywords: Malaria, Transmission, PCR, Heterogeneity, Hotspot, Peruvian Amazon

\section{Background}

Malaria remains an important public health problem in Peru, especially in the Amazonian department of Loreto where most malaria occurs [1-4]. Following the resurgence of malaria in the 1990s [5-8], which reached an historic peak of 158,115 cases in 1997 [9], the Loreto Regional Directorate of Health (LRDH) and national Peruvian Ministry of Health $(\mathrm{MoH})$ organized control efforts that were intensified with the support of international agencies, particularly the Global Fund for AIDS, Tuberculosis and Malaria (GFATM) and the US Agency for International Development (USAID) [10]. Comprehensive community-based interventions were initiated and intensified that included: delivery of long-lasting insecticidal mosquito nets (LLINs) [11], environmental management with community participation, training of community health workers and microscopists [12], and "test and treat" interventions incorporating artemisininbased combination therapy (ACT) for Plasmodium falciparum. It is thought that these interventions contributed to a reduction of microscopically-confirmed malaria cases in Loreto, from 54,291 cases in 2005 to 10,504 and 11,793 cases in 2010 and 2011, respectively [2, 13], and to an increasingly low-level, residual transmission in the region $[2,14]$.

Routine malaria control activities in the Peruvian Amazon are based on passive case detection (PCD) using light microscopy (LM) [2, 15] on patients presenting with fever or malaria-compatible illness at local health facilities. A positive LM result leads to governmentprovided, species-specific anti-malarial treatment. In areas with low and residual transmission, active, household- or field-based malaria surveillance is challenging because most infected individuals have very low-level parasitaemia, often exceeding the limit of detection of LM [16-18]. Indeed, several cross-sectional surveys in rural villages surrounding Iquitos city (capital of Loreto) have reproducibly demonstrated that the prevalence of asymptomatic parasite carriers ranges from 4 to $15 \%$, and that molecular diagnostic tools such as polymerase chain reaction (PCR) is far more sensitive than LM [14, 19-21] for identifying the presence of parasitaemia. Villages in those studies were located along the road connecting Iquitos to the Nauta district, thus presenting varying degrees of development-driven deforestation associated with increased human-biting activity of Anopheles darlingi (the main malaria vector in the Peruvian Amazon) [8]. Collectively these observations suggest that asymptomatic carriers are a hidden human infectious reservoir that, combined with favourable ecological conditions for mosquito breeding and resting sites around places where people live or work, maintain local malaria transmission in Amazonia, hence hypoendemicity and residual malaria [22-25].

The hypothesis that asymptomatic Plasmodium vivax and P. falciparum parasitaemias contribute to the maintenance of malaria hypoendemicity in the Amazon region drives the work of our Amazonia International Center of Excellence in Malaria Research (Amazonia ICEMR), which was established in 2010 as one of ten such centers supported by the National Institute of Allergy and Infectious Diseases (NIAID) of the National Institutes of Health (NIH) [26]. The Amazonia ICEMR is conducting population-based longitudinal cohort studies with the aim of assessing how sub-microscopic, asymptomatic infections contribute to maintaining transmission in epidemiological contrasting settings of the Peruvian Amazon [27]. This paper focuses on the socio-demographics and epidemiological characteristics of two contrasting exemplars of complex malaria transmission in the Peruvian Amazon, the village of Cahuide, a rural site with road-associated deforestation, and Lupuna rural site with riverine environment. Population-based estimates of $P$. vivax and $P$. falciparum prevalence by $\mathrm{LM}$ and PCR at the baseline enrollment surveys in September-October 2012 are also discussed and those estimates were related to data from routine malaria surveillance and implemented control efforts to better understand the dynamics of malaria transmission in both sites.

\section{Methods \\ Ethics statement}

Ethics clearance for the study was obtained from the Ethics Review Board of the Universidad Peruana Cayetano Heredia, Lima, Peru (SIDISI code \# 5739) and from the University of California San Diego Human Subjects Protection Program (Project \# 100765). Permissions were received from health and local authorities after explaining the purpose and procedures of the study. Signed informed consent was obtained prior the 
study enrollment to participation and blood sampling by all adults and the parents of all participating children $<18$ years. In addition to parental/guardian consent, children older than 7 years provided a signed informed assent. All the methods were carried out in accordance with approved guidelines.

\section{Study design}

A census and an epidemiological survey were conducted as baseline activities of a 3-year population-based, longitudinal cohort study in the Lupuna (LUP) and Cahuide $(\mathrm{CAH})$ sites in the northeastern Peruvian Amazon Department of Loreto. The study population included individuals aged 3 years and older who resided in study sites and agreed to participate in the cohort providing a written signed consent.

\section{Study area}

LUP site is located on the outskirts of Iquitos district, $10 \mathrm{~km}$ from downtown (latitude $03^{\circ} 44.591^{\prime} \mathrm{S}$ longitude $73^{\circ} 19.615^{\prime} \mathrm{W}$ ) (Fig. 1). It is a forested area only accessible by crossing the Nanay River by boat. LUP is comprised of three contiguous villages, Santa Rita (SR), San Jose de Lupuna town (LT), and San Pedro (SP) situated about 500-1000 $\mathrm{m}$ from the riverbanks near the administrative border between San Juan and Iquitos districts. Villagers mainly work in agricultural activities, such as cassava cultivation and charcoal production. $\mathrm{CAH}$ includes three rural villages in the southern part of San Juan district, La Habana (LH), Doce de Abril (DA) and Cahuide town $(\mathrm{CT})$, whose houses are located on both sites of the Iquitos-Nauta road between the 54th and 63th $\mathrm{km}$. These three villages were established in the 1980s after the intensification of deforestation and extension of the road connecting Iquitos city to the Nauta district. CT, the most populated $\mathrm{CAH}$ village, is a centre of palm roof production, and has a port close to the intersection between the road and the Itaya River (around 58th $\mathrm{km}$, latitude $04^{\circ} 13.785^{\prime} \mathrm{S}$ longitude $73^{\circ} 276^{\prime} \mathrm{W}$ ). The climate of study area is tropical, warm and humid with a rainy season from November to May and a dry season from June to October [14]. Annual average temperature is around

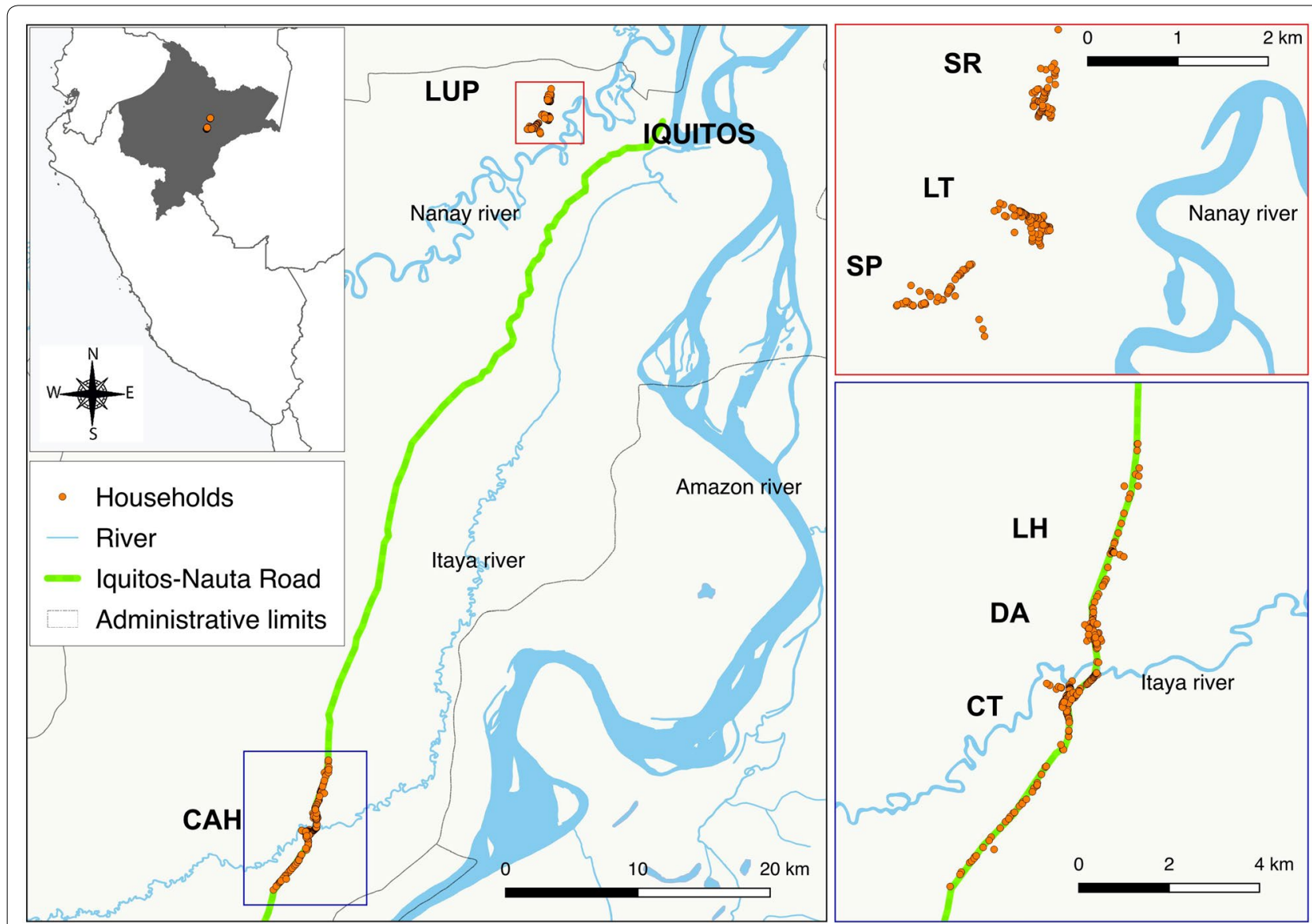

Fig. 1 Study area. Sites: Lupuna (LUP), Cahuide (CAH). Villages: Santa Rita (SR), San Juan de Lupuna town (LT), San Pedro (SP), La Habana (LH), Doce de Abril (DA), Cahuide town (CT) 
$27{ }^{\circ} \mathrm{C}$, the relative humidity above $80 \%$, with average annual rainfall of $4 \mathrm{~m}$. Anopheles darlingi is the primary malaria vector in the area [28].

Plasmodium vivax and P. falciparum cases are reported to the Ministry of Health annually for both sites throughout the entire year [28]. As in most Peruvian endemic areas, malaria surveillance in study sites relies on passive case detection (PCD). Patients presenting with fever or illness compatible with malaria are systematically tested by LM at Ministry of Health-supported LUP and CAH health posts located in LT and CT, respectively. Microscopic diagnosis is available during weekdays between 8 a.m. and 2 p.m., but not during the weekend. Plasmodium vivax malaria was treated with chloroquine (CQ) for 3 days $(10 \mathrm{mg} / \mathrm{g}$ on days 1 and 2 , and $5 \mathrm{mg} / \mathrm{kg}$ on day $3)$, plus primaquine (PQ) for 7 days $(0.5 \mathrm{mg} / \mathrm{kg} /$ day); $P$. falciparum malaria was treated with mefloquine (MQ) $(12.5 \mathrm{mg} / \mathrm{kg} /$ day for 2 days) plus artesunate (AS) (4 mg/ $\mathrm{kg} /$ day for 3 days), according to Peruvian national policy.

\section{Census and geo-referencing}

A complete census of the population in each village was conducted in July-August 2012, collecting individual data on socio-demographics (e.g. age, gender, education, occupation, socio-economic status, time living in the village), and on previous malaria episodes. Each house was identified with a unique number and geo-referenced using a handheld Global Positioning System (GPS) device (Garmin's GPSMAP 60CSx, Garmin International Inc., USA), and household characteristics collected (e.g. household size, predominant construction materials in house, ownership of animals, and availability of essential services such as potable water, sewage system and electricity). Each individual subject was given a seven-digit unique code number combining the village, household and individual code.

\section{Cohort enrollment and baseline survey}

Individuals aged 3 years and older available at the time of the baseline survey (September-October 2012) were enrolled in the study area after consenting. Whenever selected individuals were absent, the household was revisited up to four times in a period of 30 days to maximize subject participation. Each participant had the axillary temperature taken, history of fever or any other malaria symptoms were recorded, and a fingerprick blood sample collected for immediate microscopy (thick and thin blood smears) and on filter paper (Whatman grade 3, Whatman, Springfield Mill, USA) for later molecular tests. Filter paper dried blood samples were individually stored at $4{ }^{\circ} \mathrm{C}$ with desiccant until processed. Subjects with microscopically-confirmed infections were referred to health posts for treatment according to Peruvian national guidelines.

\section{Retrospective routine surveillance data}

Additionally, routine surveillance data, namely reported malaria episodes by species in Iquitos and San Juan district from 2009 to 2012 were obtained from the Regional Directorate of Health, Loreto-Ministry of Health in Iquitos. Peruvian policy mandates weekly notification of confirmed malaria cases (by standard LM) at health facilities and data aggregation at district and department level. Since malaria surveillance data could be reliably disaggregated only to the district level but not to the village level, a retrospective review of all registered individuals detected by PCD between January 2009 and December 2012 was carried out in all health facilities near the study sites. Any other surveillance in addition to routine PCD conducted in CAH and LUP in the 12 months before the survey was recorded.

\section{Laboratory procedures Microscopy}

Thick and thin smears were stained for 10 min with a $10 \%$ Giemsa solution, and parasite density was calculated by counting the number of asexual parasites for 200 white blood cells (WBC) in the thick smear, assuming a concentration of $8000 \mathrm{WBCs} / \mu \mathrm{l}$. Slides were read on site, then a day later by an expert at microscopy at the reference laboratory in Iquitos. A slide was declared negative if no malaria parasite was found after examining 100 fields [29]. Quality control was done blindly on all positive slides and $10 \%$ of randomly chosen negative slides by a senior technician at Universidad Peruana Cayetano Heredia, Instituto de Medicina Tropical-“Alexander von Humboldt" in Lima, Peru.

\section{Real time PCR}

Filter paper blood spots were cut into $\sim 6 \mathrm{~mm}^{2}$ pieces for DNA extraction using QIAamp DNA Microkit of QIAGEN following the manufacturer instructions. A quantitative real-time polymerase chain reaction (qPCR) method targeting the 18s rRNA gene region was used for molecular diagnosis, following the protocol reported by Mangold et al. [30] Primers were 5-TAACGAACGAG ATCTTAA-3 and 5-GTTCCTCTAAGAAGCTTT-3. Cycling conditions were initial denaturation at $95{ }^{\circ} \mathrm{C}$ for 2 min, followed by amplification for 45 cycles of $20 \mathrm{~s}$ at $95{ }^{\circ} \mathrm{C}, 20 \mathrm{~s}$ at $52{ }^{\circ} \mathrm{C}$, and $30 \mathrm{~s}$ at $68^{\circ} \mathrm{C}$. To confirm amplicon identify, amplification was immediately followed by a melt program consisting of $5 \mathrm{~s}$ at $65^{\circ} \mathrm{C}$ and a stepwise temperature increase of $0.5^{\circ} \mathrm{C} / \mathrm{s}$ to $95^{\circ} \mathrm{C}$. Melting curves accurately differentiated $P$. vivax from $P$. falciparum. 


\section{Data analysis}

Census and survey data were doubly entered and crosschecked in Access (Microsoft Corp, USA). Data analysis was performed using R v.2.15 software (R Development Core Team, R Foundation for Statistical Computing, Austria). Baseline characteristics between sites were compared using the Chi squared test. Species-specific parasite prevalence by LM and by PCR were estimated overall and by site, and their two-sided 95\% confidence intervals $(\mathrm{CI})$ were calculated using the Wilson score method.

The case definition for malaria parasite (Plasmodium spp.) infection was an individual with a positive PCR result regardless of symptoms. Cases were further classified as patent (detectable by LM) or sub-patent (not detectable by LM). A symptomatic infection was defined as an individual with confirmation of parasites in the blood sample at any level who also had fever or history of fever, headache, chills or general discomfort in the previous 7 days. Uni- and multivariate mixed-effects logistic regression models, with fixed effects and a random intercept that accounted for individual clustering at household, were used to determine risk factors for species-specific malaria infection in each site The following potential risk factors were assessed: age, gender, time living in the village, education level, forest-related job as main economical activity (including the intensity of these activities during the week), trip in the past month to another endemic area, the history of malaria in the past year, household overcrowding (more than three individuals sleeping per room as average in a household), low household bed net coverage $(<80 \%$ of beds covered with a net in a household), housing structure (predominant material in roof and floor), and the availability of electricity. Factors with $p$ values $<0.1$ for the Wald test in the univariate analysis were considered for inclusion in the multivariate model. Using manual backward, final models retained all factors that were significantly associated with malaria infection (Wald $p$ values $<0.05$ ). Interactions were systematically checked for up to order two. Likelihood ratio tests (LRTs) were used to assess statistical differences between nested models.

The QGIS software QGIS v.2.16 (QGIS developer team, Open Source Geospatial Foundation) was used to map all surveyed households and to classify them according to the number of household members with malaria infections identified by PCR. The SaTScan software v.9.3 (M Kulldorff and Information Management Services Inc, USA) was used to identify spatial clustering of households with malaria infections in each site, using the following characteristics: pure spatial analysis, Poisson probability model [31], latitude/longitude coordinates, report of most likely clusters with no geographical overlap of secondary clusters, maximum spatial cluster size equal to $50 \%$ of total population. The analysis was first done without adjustment for covariates, and then done including the variables identified as fixed-effect risk factors by the mixed-effects logistic regression analyses. To adjust for covariates, the number of malaria confirmed infections and the total number of screened individuals had to be specified for each particular household location and combination of covariates in the case and population files, respectively. SaTScan applied multiple circular windows across the study area, each circle representing a possible cluster. Clusters were assessed based on 999 Monte Carlo simulations to determine the probability of observed frequency of infected individuals being due to chance relative to expected frequency under the null hypothesis of no clustering. The null hypothesis was rejected if any resulting $p$ value of assessed clusters was $<0.05$ and the window with the maximum log likelihood ratio (LLR) was identified as the most likely cluster. The relative risk (RR) reported for each identified cluster was the estimated risk within the cluster divided by the estimated risk outside the cluster [31].

\section{Results}

A total of 487 households (HHs) and 2447 individuals were identified during the census in July-August 2012, distributed over the two sites as follows: LUP $(211 \mathrm{HHs}$; 1007 individuals) and CAH $(276 ; 1440)$. In addition, the distribution by village was: LT ( $95 \mathrm{HHs;} 433$ individuals), SR $(66 ; 348)$ and SP $(50 ; 226)$ for LUP, and CT $(173 ; 922)$, LH $(46 ; 224)$ and DA $(57 ; 294)$ for CAH (Table 1). The overall ratio of female to male was 0.9 ; more than half of the population in both sites was younger than 25 years.

The cohort study enrolled 1941 of the 2447 censused inhabitants $(79.3 \%)$ in $448 \mathrm{HH}(92.0 \%)$ available at the time of the baseline survey. Of these 1941 individuals, 829 (42.7\%) lived in LUP and 1117 (57.3\%) in CAH. Sociodemographic characteristics and history of past malaria episodes by site and by village are presented in Table 2 and Additional file 1: Table S1, respectively. Individuals under 25 years represented 49.3 and $54.5 \%$ of the participants respectively in LUP and CAH $(p=0.008)$. Males slightly outnumbered females (ratio female/male $=0.89$ ) without differences between sites. The proportion of participants aged $>10$ years old who have resided in the site ten or more years was significantly higher in LUP $(85.0 \%)$ than in CAH $(41.3 \%)(p<0.001)$. Among adults 18 years and older, the proportion of individuals who had completed secondary education level was higher in LUP $(47.0 \%)$ than in CAH $(32.8 \%)(p<0.001)$. The most commonly reported occupation among adults was farmers, followed by housewives, indoor laborers/employees and traders with similar proportions in both sites; security 
Table 1 Household and participants in census and baseline survey

\begin{tabular}{|c|c|c|c|c|c|c|}
\hline & \multicolumn{2}{|c|}{ Census } & \multicolumn{4}{|c|}{ Survey } \\
\hline & \multirow{2}{*}{$\begin{array}{l}\mathrm{HH} \\
\mathrm{N}\end{array}$} & \multirow{2}{*}{$\begin{array}{l}\text { Individuals } \\
\mathrm{N}\end{array}$} & \multicolumn{2}{|l|}{$\mathrm{HH}$} & \multicolumn{2}{|c|}{ Individuals } \\
\hline & & & $\mathbf{n}$ & $\%$ & $\mathrm{n}$ & $\%$ \\
\hline \multicolumn{7}{|l|}{ Lupuna (LUP) } \\
\hline Lupuna town (LT) & 95 & 433 & 88 & 92.6 & 352 & 81.3 \\
\hline Santa Rita (SR) & 66 & 348 & 63 & 95.5 & 292 & 83.9 \\
\hline San Pedro (SP) & 50 & 226 & 45 & 90.0 & 185 & 81.9 \\
\hline Total & 211 & 1007 & 196 & 92.9 & 829 & 82.3 \\
\hline \multicolumn{7}{|l|}{ Cahuide (CAH) } \\
\hline Cahuide town (CT) & 173 & 922 & 163 & 94.2 & 734 & 79.6 \\
\hline La Habana (LA) & 46 & 224 & 37 & 80.4 & 147 & 65.6 \\
\hline Doce de Abril (DA) & 57 & 294 & 52 & 91.2 & 231 & 78.6 \\
\hline Total & 276 & 1440 & 252 & 91.3 & 1112 & 77.2 \\
\hline
\end{tabular}

guards $(p=0.002)$ and loggers $(p<0.001)$ were more frequent in $\mathrm{CAH}$ than in LUP. Participants reporting having experienced malaria in their lifetime were more common in LUP (73.4\%) than in CAH (67.0\%) ( $p=0.003)$. However, this was not the case when only recent episodes were considered, with more participants reporting have had malaria episodes within the past 12 months in $\mathrm{CAH}$ (48.9\%) than in LUP $(14.1 \%)(p<0.001)$.

Table 3 and Additional file 1: Table S2 present the household characteristics of enrolled participants by site and by village, respectively. Household crowding was higher in CAH (57.6\%) than in LUP $(41.9 \%)(p<0.001)$. In both sites, most individuals lived in houses with wooden walls and roofs composed of palm leaf; concrete (brick and cement) and tin were also common building materials, especially in the LT village of LUP $(p<0.001)$ (Additional file 1: Table S2). Wooden floors built on stilts predominated in houses of $\mathrm{CAH}$, while dirt floors were more frequent in LUP, especially in SR $(p<0.001)$. Most participants had electricity at home in CAH (55.7\%), primarily those living along the road and in the DA village $(p<0.001)$; however this electrical service mainly exclusively benefited participants living in LT village in LUP $(p<0.001)$. The use of potable water for drinking and food preparation was reported by only a small proportion of individuals in LUP (15.6\%) and CAH (30.7\%), while firewood was reported as the main fuel used for cooking by most participants ( $>80 \%)$ in both sites. Moreover, most participants in both sites reported having precarious or lack of sanitation facilities, as well as lack of trash disposal systems. The majority (97.0\%) of participants in $\mathrm{CAH}$ reported that their houses were sprayed indoors with insecticide in the past 3 months, while only $12.4 \%$ reported this in LUP $(p<0.001)$. Household bed net coverage was high in both sites; the predominant material of bed nets reported by participants varied across sites. In all villages of LUP, most bed nets (about 90\%) were LLINs. In $\mathrm{CAH}$, about half of subjects reported having LLINs and half reported using non-impregnated insecticide nets made of tocuyo (non-processed cotton) or nylon.

All 1941 individuals enrolled in the cohort had samples obtained for malaria diagnosis by LM at the time of the baseline survey; most of these (1770 individuals, 92.2\%) had available sample for PCR analysis. By LM, the overall parasite prevalence was $2.1 \%$ (38 P. vivax, 2 P. falciparum infections), and by PCR 7.2\% (93 P. vivax, $35 P$. falciparum) (Table 4), with the highest figures in $\mathrm{CAH}$ site $(p<0.05)$. Of the total $38 P$. vivax infections by LM, 30 were found in $\mathrm{CAH}$ (16 with parasitaemia $<100$ parasites/ $\mu \mathrm{l}$ ), and only 8 in LUP (one with parasitaemia $<100$ parasites $/ \mu \mathrm{l}$ ); while the two microscopically confirmed $P$. falciparum infections were found in LUP (one with parasitaemia $<100$ parasites $/ \mu \mathrm{l})$. The presence of gametocytes was recorded in $15(50.0 \%)$ and $3(37.5 \%)$ of the total microscopically confirmed $P$. vivax infections in $\mathrm{CAH}$ and LUP, respectively. Gametocytes were not observed in microscopically confirmed P. falciparum infections. Parasite prevalence by PCR was higher in CAH than in LUP for $P$. vivax (6.2\% vs. $3.9 \%, \mathrm{p}=0.03)$ and for $P$. falciparum (2.6\% vs. $1.2 \%, \mathrm{p}=0.03)$. Considering PCR-confirmed infections, asymptomatic (Asy) parasite carriers were always more common than symptomatic (Sy) infections for $P$. vivax (Asy/Sy ratio: 2/1 in LUP and 3.7/1 in CAH) and for P. falciparum (Asy/Sy ratio: 1.3/1 in LUP and 4/1 in $\mathrm{CAH}$ ). Similarly, sub-patent (Spat) infections also predominated over patent (Pat) infections for both species: P. vivax (Spat/Pat ratio: $2.8 / 1$ in LUP and 3.7/1 in CAH) and $P$. falciparum malaria (Spat/Pat ratio: $1.9 / 1$ in LUP and $26 / 0$ in $\mathrm{CAH}$ ). 
Table 2 Baseline socio-demographic characteristics of study participants

\begin{tabular}{|c|c|c|c|c|c|c|}
\hline & \multicolumn{2}{|c|}{ Lupuna (LUP) } & \multicolumn{2}{|c|}{ Cahuide (CAH) } & \multicolumn{2}{|l|}{ Total } \\
\hline & $\mathrm{n}$ & $\%$ & $\mathbf{n}$ & $\%$ & $\mathrm{n}$ & $\%$ \\
\hline \multicolumn{7}{|l|}{ Gender } \\
\hline Female & 406 & 49.0 & 510 & 45.9 & 916 & 47.2 \\
\hline Male & 423 & 51.0 & 602 & 54.1 & 1025 & 52.8 \\
\hline \multicolumn{7}{|l|}{ Age (years)* } \\
\hline$<5$ & 55 & 6.6 & 88 & 7.9 & 143 & 7.4 \\
\hline $5-14.9$ & 196 & 23.6 & 336 & 30.3 & 532 & 27.5 \\
\hline $15-24.9$ & 158 & 19.1 & 191 & 17.2 & 349 & 18.0 \\
\hline $25-39.9$ & 159 & 19.2 & 215 & 19.4 & 374 & 19.3 \\
\hline $40-54.9$ & 132 & 15.9 & 164 & 14.8 & 296 & 15.3 \\
\hline$>55$ & 129 & 15.6 & 115 & 10.4 & 244 & 12.6 \\
\hline Missing & 0 & & 3 & & 3 & \\
\hline \multicolumn{7}{|c|}{ Time in village (age $\geq 10$ years)* } \\
\hline$<2$ & 26 & 3.9 & 207 & 24.6 & 233 & 15.4 \\
\hline $2-9.9$ & 74 & 11.1 & 288 & 34.2 & 362 & 24.0 \\
\hline$\geq 10$ & 567 & 85.0 & 348 & 41.3 & 915 & 60.6 \\
\hline Missing & 3 & & 3 & & 6 & \\
\hline \multicolumn{7}{|c|}{ Education (age $\geq 18$ years)* } \\
\hline None & 21 & 4.0 & 25 & 4.1 & 46 & 4.0 \\
\hline Incomplete primary & 130 & 24.9 & 200 & 32.6 & 330 & 29.0 \\
\hline Complete primary & 126 & 24.1 & 187 & 30.5 & 313 & 27.6 \\
\hline Secondary & 226 & 43.2 & 185 & 30.2 & 411 & 36.2 \\
\hline Superior & 20 & 3.8 & 16 & 2.6 & 36 & 3.2 \\
\hline Missing & 3 & & 3 & & 6 & \\
\hline \multicolumn{7}{|c|}{ Main occupation (age $\geq 18$ years)* } \\
\hline None & 29 & 5.6 & 21 & 3.4 & 50 & 4.4 \\
\hline Student & 24 & 4.6 & 9 & 1.5 & 33 & 2.9 \\
\hline Housewife & 124 & 23.9 & 145 & 23.7 & 269 & 23.8 \\
\hline Trader & 47 & 9.1 & 65 & 10.6 & 112 & 9.9 \\
\hline Labourer, employee & 72 & 13.9 & 88 & 14.4 & 160 & 14.2 \\
\hline Guardian & 2 & 0.4 & 43 & 7.0 & 45 & 4.0 \\
\hline Farmer & 178 & 34.4 & 180 & 29.4 & 358 & 31.7 \\
\hline Logger & 22 & 4.2 & 55 & 9.0 & 77 & 6.8 \\
\hline Fisher, hunter & 13 & 2.5 & 5 & 0.8 & 18 & 1.6 \\
\hline Boat driver & 7 & 1.4 & 1 & 0.2 & 8 & 0.7 \\
\hline Missing & 8 & & 4 & & 12 & \\
\hline \multicolumn{7}{|c|}{ Lifetime malaria episodes* } \\
\hline 0 & 215 & 26.6 & 365 & 33.0 & 580 & 30.3 \\
\hline 1 & 133 & 16.5 & 314 & 28.4 & 447 & 23.3 \\
\hline $2-3$ & 175 & 21.7 & 271 & 24.5 & 446 & 23.3 \\
\hline$\geq 4$ & 285 & 35.3 & 157 & 14.2 & 442 & 23.1 \\
\hline Missing & 21 & & 5 & & 26 & \\
\hline \multicolumn{7}{|c|}{ Malaria episodes (previous 12 months)* } \\
\hline 0 & 704 & 85.9 & 566 & 51.1 & 1270 & 65.9 \\
\hline 1 & 93 & 11.3 & 429 & 38.7 & 522 & 27.1 \\
\hline $2-3$ & 22 & 2.7 & 100 & 9.0 & 122 & 6.3 \\
\hline$\geq 4$ & 1 & 0.1 & 13 & 1.2 & 14 & 0.7 \\
\hline Missing & 9 & & & & & \\
\hline
\end{tabular}

* Significant difference between sites $(p<0.05)$ 
Given the relatively small number of infections detected by LM, uni- and multivariate mixed-effects logistic regression analyses were carried out only for confirmed infections by PCR for each site. In final models the estimates of the random-effects coefficients confirmed the influence of clustered sampled data at household level. In LUP, household overcrowding (i.e., more than three individuals sleeping per room as average in a household) was the only factor significantly associated with $P$. falciparum infection (OR 4.9, 95\% CI [1.0-24.6]). No significant factors were found for $P$. vivax infection (Table 5). In $\mathrm{CAH}$, age, gender and electricity availability (a proxy for income) remained independently associated with $P$. vivax malaria infection in the multivariate model (Table 6). While individuals between 15 and 39 years (AOR 2.8, 95\% CI [1.4-5.6]) and those older than 40 years (AOR 2.4, 95\% CI [1.2-5.1]) had higher odds of $P$. vivax infection than those $<15$ years, male participants were two times more likely to have a $P$. vivax infection than female participants (AOR 2.0, 95\% CI [1.1-3.6]). Moreover, the lack of electricity increased the odds of infection in household members by a factor of 1.9 (AOR 1.9, 95\% CI [1.1-3.4]) compared with individuals living in households that had available this public service. Considering $P$. falciparum, the odds of infection confirmed by PCR significantly increased at younger age (test for trend $p<0.001$ ), with individuals $<15$ years being four times more likely to have $P$. falciparum infections than adults $>40$ years (AOR 5.5, 95\% CI [1.3-24.4]). In this case, the availability of electricity was associated with highest risk of $P$. falciparum in household members (AOR 2.8, 95\% CI [1.1-7.4]) compared with individuals living in households without electricity. No association was found between $P$. vivax and $P$. falciparum infection with regard to time of residence in the village, education level, occupation, trip in the past month to another endemic area, the history of malaria in the past year, and housing characteristics of study participants.

Figures 2 and 3 show the spatial distribution of positive PCR individuals by species and for each site. Despite some aggregation of cases within adjacent houses in LUP, no significant spatial clustering of $P$. vivax and $P$. falciparum infections were identified using SaTScan (Fig. 2), mainly because of the low number of infections. However, spatial analysis demonstrated that species-specific malaria infection was non-randomly distributed in $\mathrm{CAH}$. Indeed, the most likely spatial cluster of $P$. vivax infections $(R R=4.2, p=0.028)$ was in the southern part of $\mathrm{CT}$ village (Fig. 3a), including 59 surveyed individuals with available PCR results (5.8\% of total in CAH) in 16 households (6.6\% of total). The cluster represented $20.6 \%$ $(13 / 63)$ of all $P$. vivax confirmed infections by PCR. However, this cluster disappeared when the spatial analysis was adjusted for gender, age and electricity availability (factors associated with the infection according to risk factor analysis). For $P$. falciparum, the most likely cluster adjusted for age and electricity availability was the closest area to the fluvial port in $C T(R R=6.6, p=0.04)$. With a radius of 99 meters, the cluster included 61 individuals $(6.0 \%$ of the total) in 14 households (5.7\% of the total) (Fig. 3b). This cluster represented 30.8\% (8/26) of all $P$. falciparum confirmed infections by PCR. Notably, most individuals and households of the adjusted cluster were included within a previously identified bigger cluster (radius $=180 \mathrm{~m}$ ) without adjustment for covariates.

The retrospective analysis of reported malaria cases between 2009 and 2012 showed that the malaria incidence in LUP varied across years, with some periods (mainly in year 2009) not following the same trends of malaria incidence compared to the Iquitos district (Fig. 4a). Despite this temporal heterogeneity in the malaria incidence in LUP, a seasonal increase of malaria cases was annually identified between April and July from 2010 and 2012. In 2012, malaria cases from LUP villages (124 P. vivax, 7 P. falciparum) represented about $15 \%$ of the total 880 reported cases in Iquitos district. Regarding malaria intervention efforts, deliveries of LLINs by GFATM's PAMAFRO malaria project in 2008 and 2010 were the main malaria control intervention in LUP during the evaluated period. On the other hand, malaria cases in CAH between 2009 and 2011 occurred with stochastic patterns (with no more than $70 P$. vivax and 10 P. falciparum reported cases per year), and did not follow the same trends of the malaria incidence than San Juan district during that period (Fig. 4b). The rapid increase of malaria cases in study villages of CAH since May 2012 following intensive and prolonged rains triggered comprehensive control efforts leaded by RHDL-MoH, such as successive mass-screening interventions with $\mathrm{LM}$ and treatment of confirmed infections (four rounds between May and August 2012), indoor spraying with residual insecticide (more than $90 \%$ of household coverage according to RHDL-MoH in May 2012), and the distribution of LLINs (one per household in July 2012) (Additional file 2: Figure S1). Households in CAH had previously received LLINs from PAMAFRO project only in 2007 [11], reaching high coverage levels. Although the outbreak was partially controlled by August 2012, malaria cases increased again in November-December 2012. At the end of the year, malaria cases (1221 P. vivax cases and 28 P. falciparum cases) from $\mathrm{CAH}$ villages accounted for about $35 \%$ of the total 3617 reported cases in San Juan district in 2012.

\section{Discussion}

The baseline analysis presented here of a populationbased, longitudinal malaria cohort study in two contrasting ecological villages in the Peruvian Amazon 
Table 3 Baseline household characteristics of study participants

\begin{tabular}{|c|c|c|c|c|c|c|}
\hline & \multicolumn{2}{|c|}{ Lupuna (LUP) } & \multicolumn{2}{|c|}{ Cahuide (CAH) } & \multicolumn{2}{|l|}{ Total } \\
\hline & $\mathbf{n}$ & $\%$ & $\mathbf{n}$ & $\%$ & $\mathbf{n}$ & $\%$ \\
\hline \multicolumn{7}{|c|}{ Overcrowding (>3 persons/bedroom)* } \\
\hline No & 482 & 58.1 & 471 & 42.4 & 953 & 49.1 \\
\hline Yes & 347 & 41.9 & 639 & 57.6 & 986 & 50.9 \\
\hline Missing & 0 & & 2 & & 2 & \\
\hline \multicolumn{7}{|l|}{ Wall material* } \\
\hline Brick, cement & 130 & 15.7 & 51 & 4.6 & 181 & 9.3 \\
\hline Wood & 629 & 75.9 & 919 & 82.8 & 1548 & 79.8 \\
\hline Palm & 47 & 5.7 & 61 & 5.5 & 108 & 5.6 \\
\hline Tin, other & 23 & 2.8 & 79 & 7.1 & 102 & 5.3 \\
\hline Missing & 0 & & 2 & & 2 & \\
\hline \multicolumn{7}{|l|}{ Roof material* } \\
\hline Tin & 271 & 32.7 & 157 & 14.2 & 428 & 22.1 \\
\hline Palm & 558 & 67.3 & 947 & 85.8 & 1505 & 77.9 \\
\hline Missing & 0 & & 8 & & 8 & \\
\hline \multicolumn{7}{|l|}{ Floor material* } \\
\hline Cement & 203 & 24.5 & 141 & 12.7 & 344 & 17.7 \\
\hline Wood & 98 & 11.8 & 640 & 57.7 & 738 & 38.1 \\
\hline Dirt & 528 & 63.7 & 329 & 29.6 & 857 & 44.2 \\
\hline Missing & 0 & & 2 & & 2 & \\
\hline \multicolumn{7}{|l|}{ Electricity* } \\
\hline Yes & 298 & 35.9 & 618 & 55.7 & 916 & 47.2 \\
\hline No & 531 & 64.1 & 492 & 44.3 & 1023 & 52.8 \\
\hline Missing & 0 & & 2 & & 2 & \\
\hline \multicolumn{7}{|l|}{ Potable water for drinking* } \\
\hline Yes & 129 & 15.6 & 337 & 30.7 & 466 & 24.2 \\
\hline No & 700 & 84.4 & 760 & 69.3 & 1460 & 75.8 \\
\hline Missing & 0 & & 15 & & 15 & \\
\hline \multicolumn{7}{|l|}{ Source of water* } \\
\hline Piped into dwelling & 6 & 0.7 & 44 & 4.1 & 50 & 2.6 \\
\hline Public tap & 272 & 32.8 & 292 & 27.5 & 564 & 29.8 \\
\hline Open well & 309 & 37.3 & 358 & 33.7 & 667 & 35.3 \\
\hline River, rain & 242 & 29.2 & 368 & 34.7 & 610 & 32.3 \\
\hline Missing & 0 & & 50 & & 50 & \\
\hline \multicolumn{7}{|l|}{ Sanitation facility* } \\
\hline Flush toilet & 4 & 0.5 & 3 & 0.3 & 7 & 0.4 \\
\hline Pit latrine & 168 & 20.4 & 306 & 27.6 & 474 & 24.5 \\
\hline Ground hole, cesspool & 279 & 33.9 & 518 & 46.7 & 797 & 41.2 \\
\hline No facility, field & 373 & 45.3 & 283 & 25.5 & 656 & 33.9 \\
\hline Missing & 5 & & 2 & & 7 & \\
\hline \multicolumn{7}{|l|}{ Trash disposal* } \\
\hline Burning trash & 240 & 29.0 & 467 & 42.4 & 707 & 36.6 \\
\hline Bury trash & 56 & 6.8 & 163 & 14.8 & 219 & 11.3 \\
\hline Field, river & 510 & 61.5 & 466 & 42.3 & 976 & 50.6 \\
\hline Other & 23 & 2.8 & 5 & 0.5 & 28 & 1.5 \\
\hline Missing & 0 & & 11 & & 11 & \\
\hline \multicolumn{7}{|l|}{ Cooking fuel* } \\
\hline Gas & 22 & 2.7 & 40 & 3.6 & 62 & 3.2 \\
\hline Kerosene, charcoal & 13 & 1.6 & 137 & 12.4 & 150 & 7.7 \\
\hline
\end{tabular}


Table 3 continued

\begin{tabular}{|c|c|c|c|c|c|c|}
\hline & \multicolumn{2}{|c|}{ Lupuna (LUP) } & \multicolumn{2}{|c|}{ Cahuide (CAH) } & \multicolumn{2}{|l|}{ Total } \\
\hline & $\mathrm{n}$ & $\%$ & $\mathbf{n}$ & $\%$ & $\mathbf{n}$ & $\%$ \\
\hline Firewood & 793 & 95.8 & 932 & 84.0 & 1725 & 89.1 \\
\hline Missing & 1 & & 3 & & 4 & \\
\hline \multicolumn{7}{|c|}{ Insecticide sprayed (previous 3 months)* } \\
\hline Yes & 93 & 12.4 & 988 & 97.0 & 1081 & 61.1 \\
\hline No & 656 & 87.6 & 31 & 3.0 & 687 & 38.9 \\
\hline Missing & 80 & & 93 & & 173 & \\
\hline \multicolumn{7}{|c|}{ Bednet coverage (bednets/beds), \% } \\
\hline$<80$ & 28 & 3.4 & 32 & 2.9 & 60 & 3.1 \\
\hline$\geq 80$ & 801 & 96.6 & 1078 & 97.1 & 1879 & 96.9 \\
\hline Missing & 0 & & 2 & & 2 & \\
\hline \multicolumn{7}{|c|}{ Bednet material* } \\
\hline None & 0 & 0.0 & 2 & 0.2 & 2 & 0.1 \\
\hline Tocuyo & 41 & 4.9 & 400 & 36.1 & 441 & 22.8 \\
\hline Nylon & 33 & 4.0 & 124 & 11.2 & 157 & 8.1 \\
\hline LLINs & 755 & 91.1 & 557 & 50.2 & 1312 & 67.7 \\
\hline Other & 0 & 0.0 & 26 & 2.3 & 26 & 1.3 \\
\hline Missing & 0 & & 3 & & 3 & \\
\hline
\end{tabular}

* Significant difference between sites $(p<0.05)$

Table 4 Malaria prevalence (by LM and PCR) by study site

\begin{tabular}{|c|c|c|c|c|c|c|c|c|c|c|c|c|}
\hline & \multicolumn{4}{|c|}{ Lupuna (LUP) } & \multicolumn{4}{|c|}{ Cahuide (CAH) } & \multicolumn{4}{|l|}{ Total } \\
\hline & $\mathbf{n}$ & \multirow[t]{2}{*}{$\%$} & \multicolumn{2}{|c|}{$\%[95 \% \mathrm{Cl}]$} & $\mathbf{n}$ & \multirow[t]{2}{*}{$\%$} & \multicolumn{2}{|c|}{$\%[95 \% \mathrm{Cl}]$} & $\mathrm{n}$ & \multirow[t]{2}{*}{$\%$} & \multicolumn{2}{|c|}{$\%[95 \% \mathrm{Cl}]$} \\
\hline \multicolumn{10}{|l|}{ Microscopy } & & & \\
\hline Total analysed samples (N) & 829 & & & & 1112 & & & & 1941 & & & \\
\hline P. vivax & 8 & 1.0 & 0.4 & 2.0 & 30 & 2.7 & 1.9 & 3.9 & 38 & 2.0 & 1.4 & 2.7 \\
\hline P. falciparum & 2 & 0.2 & 0.0 & 1.0 & 0 & 0.0 & & & 2 & 0.1 & 0.0 & 0.4 \\
\hline Overall** & 10 & 1.2 & 0.6 & 2.3 & 30 & 2.7 & 1.9 & 3.9 & 40 & 2.1 & 1.5 & 2.8 \\
\hline Asymptomatic P. vivax & 3 & 0.4 & 0.1 & 1.1 & 24 & 2.2 & 1.4 & 3.2 & 27 & 1.4 & 0.9 & 2.0 \\
\hline Symptomatic P. vivax & 5 & 0.6 & 0.2 & 1.5 & 6 & 0.5 & 0.2 & 1.2 & 11 & 0.6 & 0.3 & 1.0 \\
\hline Asymptomatic $P$. falciparum & 1 & 0.1 & 0.0 & 0.8 & 0 & 0.0 & & & 1 & 0.1 & 0.0 & 0.3 \\
\hline Symptomatic $P$. falciparum & 1 & 0.1 & 0.0 & 0.8 & 0 & 0.0 & & & 1 & 0.1 & 0.0 & 0.3 \\
\hline \multicolumn{13}{|l|}{$P C R$} \\
\hline Total analysed samples (N) & 777 & & & & 1013 & & & & 1790 & & & \\
\hline P. vivax ${ }^{*}$ & 30 & 3.9 & 2.7 & 5.5 & 63 & 6.2 & 4.8 & 7.9 & 93 & 5.2 & 4.2 & 6.4 \\
\hline P. falciparum* & 9 & 1.2 & 0.6 & 2.3 & 26 & 2.6 & 1.7 & 3.8 & 35 & 2.0 & 1.4 & 2.7 \\
\hline Overall** & 39 & 5.0 & 3.6 & 6.9 & 89 & 8.8 & 7.2 & 10.7 & 128 & 7.2 & 6.0 & 8.5 \\
\hline Asymptomatic P. vivax & 20 & 2.6 & 1.6 & 4.0 & 53 & 5.2 & 4.0 & 6.8 & 73 & 4.1 & 3.2 & 5.1 \\
\hline Symptomatic P. vivax & 10 & 1.3 & 0.7 & 2.4 & 10 & 1.0 & 0.5 & 1.9 & 20 & 1.1 & 0.7 & 1.8 \\
\hline Asymptomatic P. falciparum & 5 & 0.6 & 0.2 & 1.6 & 23 & 2.3 & 1.5 & 3.4 & 28 & 1.6 & 1.1 & 2.3 \\
\hline Symptomatic P. falciparum & 4 & 0.5 & 0.2 & 1.4 & 3 & 0.3 & 0.1 & 0.9 & 7 & 0.4 & 0.2 & 0.8 \\
\hline Sub-patent $P$. vivax & 22 & 2.8 & 1.8 & 4.3 & 41 & 4.0 & 3.0 & 5.5 & 63 & 3.5 & 2.7 & 4.5 \\
\hline Patent $P$. vivax & 8 & 1.0 & 0.5 & 2.1 & 22 & 2.2 & 1.4 & 3.3 & 30 & 1.7 & 1.2 & 2.4 \\
\hline Sub-patent P. falciparum & 8 & 1.0 & 0.5 & 2.1 & 26 & 2.6 & 1.7 & 3.8 & 34 & 1.9 & 1.3 & 2.7 \\
\hline Patent P. falciparum & 1 & 0.1 & 0.0 & 0.8 & 0 & 0.0 & & & 1 & 0.1 & 0.0 & 0.4 \\
\hline
\end{tabular}

* Significant difference between sites $(p<0.05)$ 
Table 5 Univariate risk factor analysis for $P$. vivax and $P$. falciparum infection in Lupuna (LUP)

\begin{tabular}{|c|c|c|c|c|c|c|c|c|c|c|c|c|}
\hline & \multicolumn{6}{|c|}{ P. vivax by PCR } & \multicolumn{6}{|c|}{ P. falciparum by PCR } \\
\hline & $\mathbf{n}$ & $\mathrm{N}$ & $\%$ & OR & \multicolumn{2}{|c|}{ OR $[95 \% \mathrm{Cl}]$} & $\mathbf{n}$ & $\mathbf{N}$ & $\%$ & OR & \multicolumn{2}{|c|}{ OR $[95 \% \mathrm{Cl}]$} \\
\hline \multicolumn{13}{|l|}{ Gender } \\
\hline Female & 13 & 382 & 3.4 & Ref & & & 3 & 382 & 0.8 & Ref & & \\
\hline Male & 17 & 395 & 4.3 & 1.3 & 0.6 & 2.7 & 6 & 395 & 1.5 & 1.9 & 0.5 & 7.7 \\
\hline \multicolumn{13}{|l|}{ Age (years) } \\
\hline$<15$ & 9 & 234 & 3.8 & Ref & & & 5 & 234 & 2.1 & 6.3 & 0.7 & 58.7 \\
\hline $15-39$ & 15 & 291 & 5.2 & 1.4 & 0.6 & 3.2 & 3 & 291 & 1.0 & 2.7 & 0.3 & 27.6 \\
\hline$\geq 40$ & 6 & 252 & 2.4 & 0.6 & 0.2 & 1.7 & 1 & 252 & 0.4 & Ref & & \\
\hline \multicolumn{13}{|l|}{ Time in village (years) } \\
\hline$<10$ & 7 & 242 & 2.9 & Ref & & & 3 & 242 & 1.2 & Ref & & \\
\hline$\geq 10$ & 23 & 535 & 4.3 & 1.5 & 0.6 & 3.6 & 6 & 535 & 1.1 & 0.9 & 0.2 & 3.7 \\
\hline \multicolumn{13}{|l|}{ Education } \\
\hline None & 3 & 89 & 3.4 & Ref & & & 1 & 89 & 1.1 & Ref & & \\
\hline Incomplete primary & 6 & 245 & 2.4 & 0.7 & 0.2 & 2.9 & 2 & 245 & 0.8 & 0.7 & 0.1 & 8.6 \\
\hline Complete primary & 6 & 153 & 3.9 & 1.2 & 0.3 & 4.8 & 2 & 153 & 1.3 & 1.1 & 0.1 & 13.3 \\
\hline Secondary & 15 & 290 & 5.2 & 1.6 & 0.4 & 5.5 & 4 & 290 & 1.4 & 1.2 & 0.1 & 11.8 \\
\hline \multicolumn{13}{|l|}{ Forest-related job } \\
\hline No & 21 & 563 & 3.7 & Ref & & & 7 & 563 & 1.2 & Ref & & \\
\hline Yes ( $\leq 5$ day/week) & 8 & 153 & 5.2 & 1.4 & 0.6 & 3.3 & 2 & 153 & 1.3 & 0.9 & 0.2 & 4.9 \\
\hline Yes (>5 day/week) & 0 & 56 & 0.0 & NC & & & 0 & 56 & 0.0 & NC & & \\
\hline \multicolumn{13}{|l|}{ Trip previous month } \\
\hline No & 30 & 771 & 3.9 & Ref & & & 9 & 771 & 1.2 & Ref & & \\
\hline Yes & 0 & 6 & 0.0 & NC & & & 0 & 6 & 0.0 & NC & & \\
\hline \multicolumn{13}{|c|}{ Malaria episodes (previous 12 months) } \\
\hline 0 & 25 & 662 & 3.8 & Ref & & & 9 & 662 & 1.4 & Ref & & \\
\hline$\geq 1$ episodes & 5 & 107 & 4.7 & 1.2 & 0.5 & 3.3 & 0 & 107 & 0.0 & NC & & \\
\hline \multicolumn{13}{|c|}{ Overcrowding (>3 persons/bedroom) } \\
\hline No & 17 & 452 & 3.8 & Ref & & & 2 & 452 & 0.4 & Ref & & \\
\hline Yes & 13 & 325 & 4.0 & 1.1 & 0.5 & 2.2 & 7 & 325 & 2.2 & $4.9^{*}$ & 1.0 & 24.6 \\
\hline \multicolumn{13}{|l|}{ Bednet coverage, $\%$} \\
\hline$\geq 80$ & 30 & 751 & 4.0 & Ref & & & 9 & 751 & 1.2 & Ref & & \\
\hline$<80$ & 0 & 26 & 0.0 & NC & & & 0 & 26 & 0.0 & NC & & \\
\hline \multicolumn{13}{|l|}{ Roof material } \\
\hline Calamine & 9 & 245 & 3.7 & Ref & & & 2 & 245 & 0.8 & Ref & & \\
\hline Palm & 21 & 532 & 3.9 & 1.1 & 0.5 & 2.4 & 7 & 532 & 1.3 & 1.6 & 0.3 & 8.3 \\
\hline \multicolumn{13}{|l|}{ Floor material } \\
\hline Cement & 5 & 184 & 2.7 & Ref & & & 1 & 184 & 0.5 & Ref & & \\
\hline Wood & 6 & 93 & 6.5 & 2.5 & 0.7 & 8.3 & 0 & 93 & 0.0 & NC & & \\
\hline Dirt & 19 & 500 & 3.8 & 1.4 & 0.5 & 3.8 & 8 & 500 & 1.6 & 2.9 & 0.2 & 38.1 \\
\hline \multicolumn{13}{|l|}{ Electricity } \\
\hline Yes & 13 & 271 & 4.8 & Ref & & & 1 & 271 & 0.4 & Ref & & \\
\hline No & 17 & 506 & 3.4 & 0.7 & 0.3 & 1.4 & 8 & 506 & 1.6 & 4.3 & 0.5 & 36.0 \\
\hline
\end{tabular}

Random-effects variance for $P$. falciparum model $=0.62$ (including only overcrowding)

Ref reference, $N C$ non calculated

${ }^{*} \mathrm{p}<0.05$

indicates substantial prevalence of malaria parasitaemia in the region and is an important benchmark for ongoing longitudinal studies. The riverine rural site, Lupuna
(LUP), is home to a fairly stable population ( $85 \%$ of individuals $>10$ years having lived in the village 10 years or more). Here, the combined analysis of survey findings 
Table 6 Univariate and multivariate risk factor analysis for $P$. vivax and $P$. falciparum infection in Cahuide (CAH)

\begin{tabular}{|c|c|c|c|c|c|c|c|c|c|c|c|c|c|c|c|c|c|c|}
\hline \multirow{2}{*}{ Gender } & \multicolumn{9}{|c|}{ P. vivax by PCR } & \multicolumn{9}{|c|}{ P. falciparum by PCR } \\
\hline & \multirow{3}{*}{$\begin{array}{l}\mathbf{n} \\
\\
19 \\
44\end{array}$} & \multirow{2}{*}{$\begin{array}{l}\mathbf{N} \\
471\end{array}$} & \multirow{2}{*}{$\begin{array}{l}\% \\
4.0\end{array}$} & \multirow{2}{*}{$\begin{array}{l}\text { OR } \\
\text { Ref }\end{array}$} & \multicolumn{2}{|c|}{ OR $[95 \% \mathrm{Cl}]$} & & \multicolumn{2}{|c|}{$\begin{array}{l}\text { AOR } \\
{[95 \% \mathrm{Cl}]}\end{array}$} & $\mathbf{n}$ & $\mathrm{N}$ & $\%$ & OR & \multicolumn{2}{|c|}{ OR $[95 \% \mathrm{Cl}]$} & AOR & \multicolumn{2}{|c|}{$\begin{array}{l}\text { AOR } \\
{[95 \% \mathrm{CI}]}\end{array}$} \\
\hline Female & & & & & & & Ref & & & 12 & 471 & 2.5 & Ref & & & & & \\
\hline Male & & 542 & 8.1 & 2.1 & 1.2 & 3.8 & $2.0^{*}$ & 1.1 & 3.6 & 14 & 542 & 2.6 & 1.0 & 0.5 & 2.3 & & & \\
\hline \multicolumn{19}{|l|}{ Age (years) } \\
\hline$<15$ & 13 & 401 & 3.2 & Ref & & & Ref & & & 17 & 401 & 4.2 & $5.6^{*}$ & 1.3 & 24.8 & $5.5^{*}$ & 1.3 & 24.4 \\
\hline $15-39$ & 30 & 362 & 8.3 & $2.8^{*}$ & 1.4 & 5.5 & $2.8^{*}$ & 1.4 & 5.6 & 7 & 362 & 1.9 & 2.4 & 0.5 & 12.0 & 2.3 & 0.5 & 11.3 \\
\hline$\geq 40$ & 20 & 249 & 8.0 & $2.6^{*}$ & 1.2 & 5.5 & $2.4^{*}$ & 1.2 & 5.1 & 2 & 249 & 0.8 & Ref & & & Ref & & \\
\hline Time in village (years) & & & & & & & & & & & & & & & & & & \\
\hline$<2$ & 17 & 237 & 7.2 & Ref & & & & & & 5 & 237 & 2.1 & Ref & & & & & \\
\hline $2-9$ & 26 & 448 & 5.8 & 0.8 & 0.4 & 1.7 & & & & 15 & 448 & 3.3 & 1.6 & 0.5 & 4.6 & & & \\
\hline$\geq 10$ & 20 & 328 & 6.1 & 0.9 & 0.4 & 1.9 & & & & 6 & 328 & 1.8 & 0.8 & 0.2 & 2.8 & & & \\
\hline Education & & & & & & & & & & & & & & & & & & \\
\hline None & 7 & 135 & 5.2 & Ref & & & & & & 5 & 135 & 3.7 & Ref & & & & & \\
\hline Incomplete primary & 23 & 397 & 5.8 & 1.2 & 0.5 & 3.0 & & & & 10 & 397 & 2.5 & 0.7 & 0.2 & 2.0 & & & \\
\hline Complete primary & 17 & 242 & 7.0 & 1.6 & 0.6 & 4.1 & & & & 5 & 242 & 2.1 & 0.5 & 0.1 & 1.9 & & & \\
\hline Secondary & 16 & 237 & 6.8 & 1.5 & 0.6 & 3.9 & & & & 6 & 237 & 2.5 & 0.7 & 0.2 & 2.2 & & & \\
\hline Forest-related job & & & & & & & & & & & & & & & & & & \\
\hline No & 37 & 750 & 4.9 & Ref & & & Ref & & & 25 & 750 & 3.3 & Ref & & & & & \\
\hline Yes ( $\leq 5$ day/week) & 4 & 38 & 10.5 & 1.6 & 0.8 & 3.1 & 1.1 & 0.3 & 3.3 & 0 & 183 & 0.0 & NC & & & & & \\
\hline Yes (>5 day/week) & 16 & 168 & 9.5 & $3.4^{*}$ & 1.6 & 7.2 & 1.1 & 0.6 & 2.3 & 1 & 79 & 1.3 & 0.4 & 0.1 & 3.4 & & & \\
\hline Trip previous month & & & & & & & & & & & & & & & & & & \\
\hline No & 61 & 969 & 6.3 & Ref & & & & & & 26 & 969 & 2.7 & Ref & & & & & \\
\hline Yes & 2 & 44 & 4.5 & 0.7 & 0.2 & 3.2 & & & & 0 & 44 & 0.0 & NC & & & & & \\
\hline Malaria episodes (prev & bus 1 & mont & & & & & & & & & & & & & & & & \\
\hline 0 & 31 & 499 & 6.2 & Ref & & & & & & 16 & 499 & 3.2 & Ref & & & & & \\
\hline$\geq 1$ episodes & 32 & 512 & 6.3 & 1.0 & 0.6 & 1.7 & & & & 10 & 512 & 2.0 & 0.6 & 0.3 & 1.3 & & & \\
\hline Overcrowding ( $>3$ per & ons/b & edroor & & & & & & & & & & & & & & & & \\
\hline No & 23 & 425 & 5.4 & Ref & & & & & & 14 & 425 & 3.3 & Ref & & & & & \\
\hline Yes & 40 & 588 & 6.8 & 1.3 & 0.7 & 2.3 & & & & 12 & 588 & 2.0 & 0.6 & 0.3 & 1.4 & & & \\
\hline Bednet coverage, $\%$ & & & & & & & & & & & & & & & & & & \\
\hline$\geq 80$ & 60 & 985 & 6.1 & Ref & & & & & & 26 & 985 & 2.6 & Ref & & & & & \\
\hline$<80$ & 3 & 28 & 10.7 & 2.1 & 0.5 & 8.8 & & & & 0 & 28 & 0.0 & NC & & & & & \\
\hline Roof material & & & & & & & & & & & & & & & & & & \\
\hline Calamine & 14 & 144 & 9.7 & Ref & & & & & & 7 & 144 & 4.9 & Ref & & & & & \\
\hline Palm & 49 & 865 & 5.7 & 0.6 & 0.3 & 1.1 & & & & 19 & 865 & 2.2 & 0.4 & 0.2 & 1.1 & & & \\
\hline Floor material & & & & & & & & & & & & & & & & & & \\
\hline Cement & 9 & 122 & 7.4 & Ref & & & & & & 6 & 122 & 4.9 & Ref & & & & & \\
\hline Wood & 32 & 590 & 5.4 & 0.7 & 0.3 & 1.6 & & & & 14 & 590 & 2.4 & 0.5 & 0.2 & 1.3 & & & \\
\hline Dirt & 22 & 301 & 7.3 & 1.0 & 0.4 & 2.5 & & & & 6 & 301 & 2.0 & 0.4 & 0.1 & 1.3 & & & \\
\hline Electricity & & & & & & & & & & & & & & & & & & \\
\hline Yes & 26 & 560 & 4.6 & Ref & & & Ref & & & 20 & 560 & 3.6 & 2.7 & 1.1 & 7.1 & 2.8 & 1.1 & 7.4 \\
\hline No & 37 & 453 & 8.2 & $1.9^{*}$ & 1.0 & 3.3 & 1.9 & 1.1 & 3.4 & 6 & 453 & 1.3 & Ref & & & Ref & & \\
\hline
\end{tabular}

Random-effects variance for adjusted $P$. vivax model $=0.48$

Random-effects variance for adjusted $P$. falciparum model $=0.36$

Ref reference, $N C$ non calculated

* $\mathrm{p}<0.05$ 


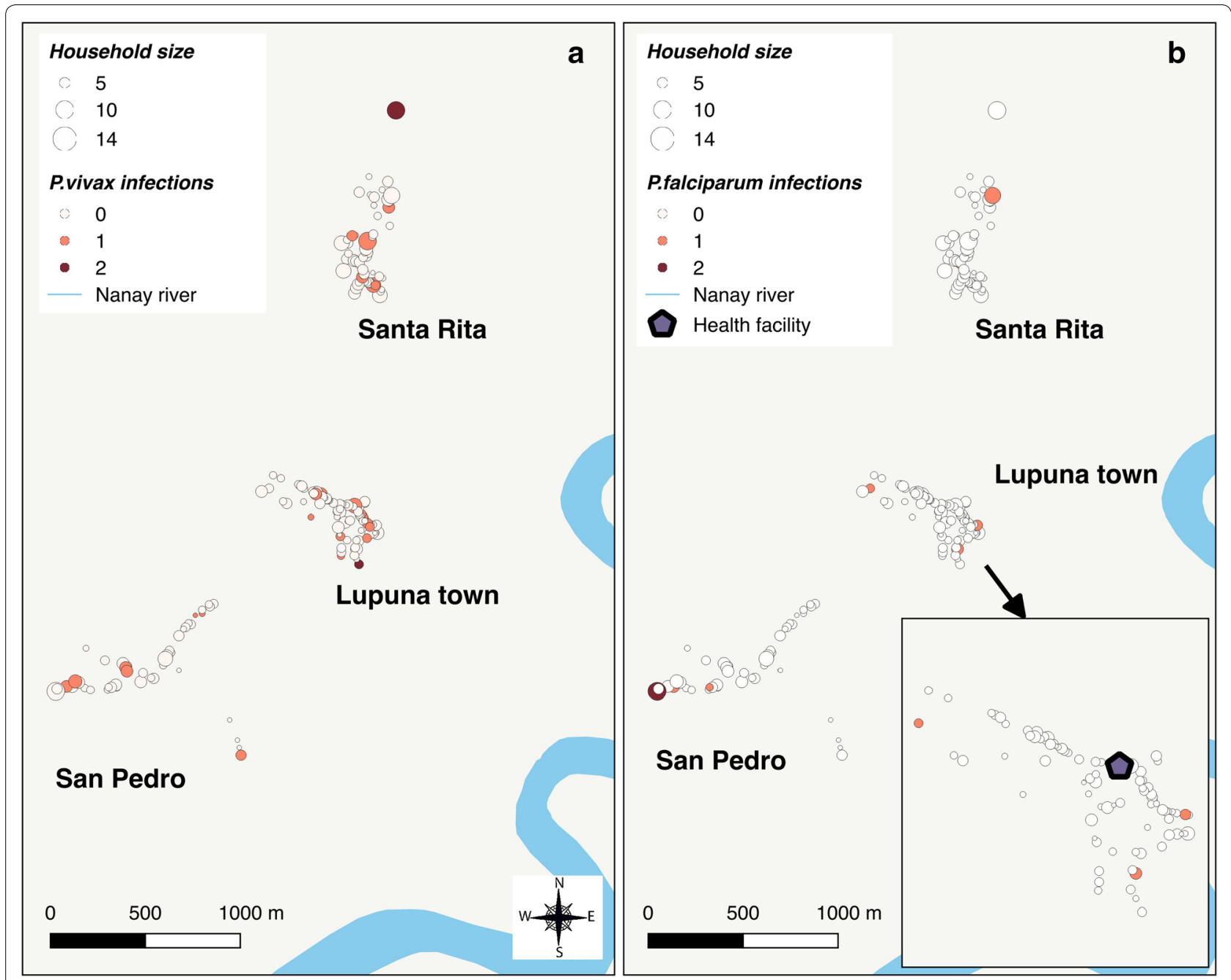

Fig. 2 Distribution of P. vivax-(a) and P. falciparum- (b) infected individuals in Lupuna

and routine reported malaria incidence suggests that malaria transmission has long occurred with primarily seasonal patterns. In contrast, Cahuide $(\mathrm{CAH})$, a rural site with road-driven deforestation and a more transient population (about $60 \%$ ), has experienced a notable and concerning increase of cases since May 2012 that compelled the regional government to carry out intensive outbreak control measures until August 2012 (1 month before the survey). Low parasite rates were observed in both sites during the survey, with high predominance of asymptomatic and sub-patent infections over symptomatic and patent infections. Moreover, the site-specific analysis of malaria prevalence and reported incidence suggested a high degree of heterogeneity at the microgeographic level and over time for both $P$. falciparum and $P$. vivax.
Community surveys for determining malaria parasite carriage are commonly used to estimate malaria transmission in endemic areas [32, 33]. Because cross-sectional designs only include collecting data at one time point related to a specific outcome of interest (malaria), they are unable to capture the variations in malaria transmission over time (i.e., seasonal, epidemic or sporadic patterns in malaria transmission) [32]. Therefore, a better interpretation of the obtained prevalence rates in LUP and $\mathrm{CAH}$ requires understanding the appropriate context (riverine, road-associated) in Amazonia, and analysis of past trends in malaria incidence in relation with important events and factors influencing malaria transmission. Such analysis will be deepened by the longitudinally acquired data over the course of our ICEMR project (e.g., epidemiological, entomological, and ecological data), and 


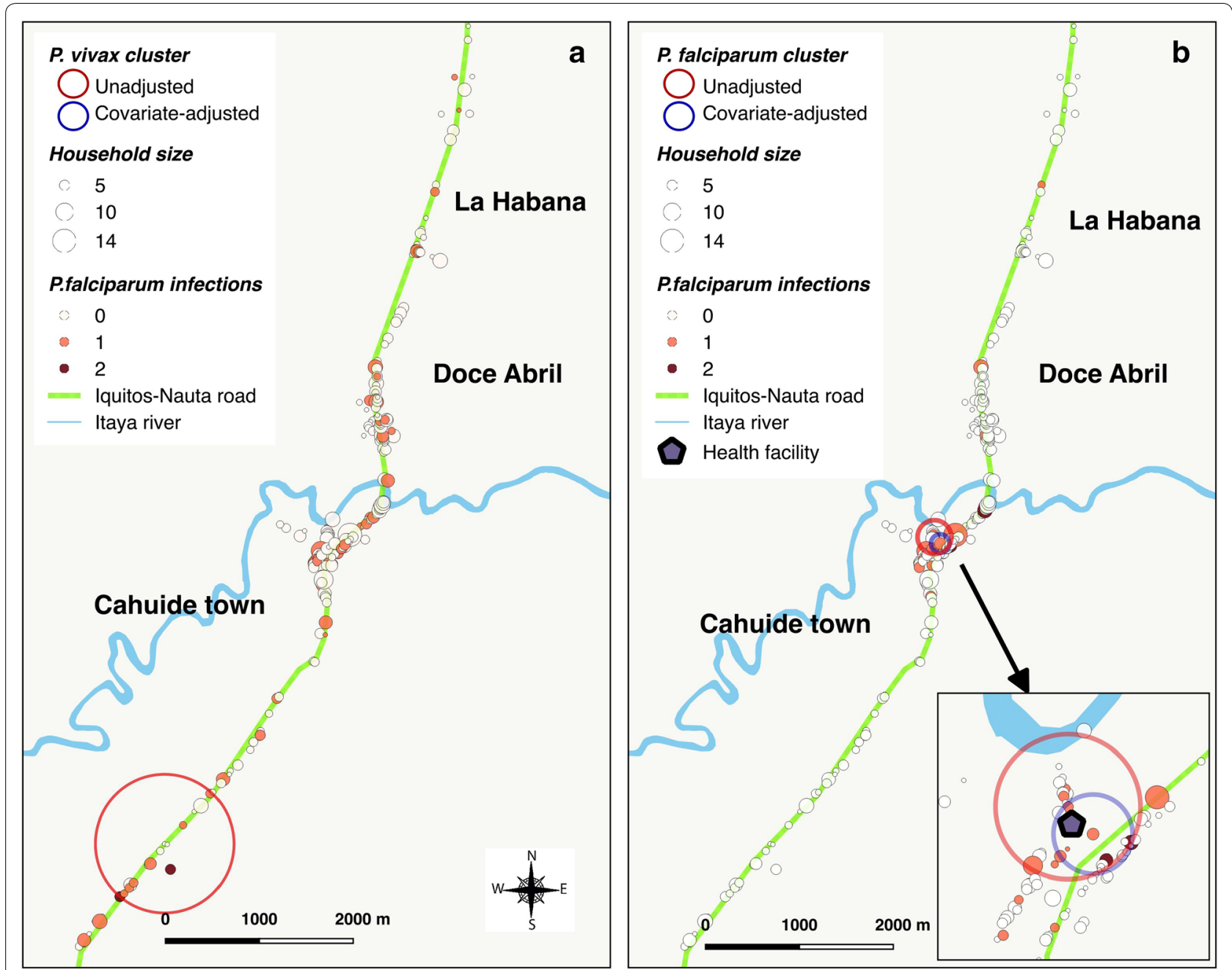

Fig. 3 Distribution of P. vivax- (a) and P. falciparum- (b) infected individuals in Cahuide (CAH) with location of significant spatial clusters

will underlie the implementation of future control and elimination strategies.

The richness of these datasets is important to consider with regard to how future analyses will guide antimalaria interventions. In riverine, rural LUP, malaria prevalence by PCR may indicate the seasonal-time dependent parasite carriage level in an endemic area (i.e., low seasonal transmission during the baseline survey) with no major recent changes in the population sociodemographics and in local control measures. In contrast, in road/deforestation and riverine rural $\mathrm{CAH}$, prevalence of parasite carriers (with confirmed gametocytaemia by LM in some of them) reflects the parasite reservoir that enables persistence of malaria transmission by both $P$. vivax and $P$. falciparum. This was observed here to have occurred despite the intensive response from RHDL$\mathrm{MoH}$ to a severe malaria outbreak from May to August
2012. These interpretations are further supported by a recently published entomological study of our Amazonian ICEMR that found that the highest monthly entomological inoculation rates (EIRs) are associated with seasonal transmission in both sites, with an important factor being seasonally high river levels that enable mosquito breeding [28]. Indeed, the entomological evaluation confirmed the presence of infected An. darlingi (by both $P$. vivax and $P$. falciparum) and higher human biting rates (HBRs) in LUP between February and June (maximum EIR in April) in successive years 2011 and 2012; while for $\mathrm{CAH}$, the highest monthly EIR (2.52) with also confirmed $P$. vivax- and P. falciparum-infected An. darlingi occurred during the 2012 malaria outbreak. Interestingly, despite decreased HBR levels leading to a much lower estimated EIR in CAH in October 2012 (period of baseline survey), the entomological study found a high 

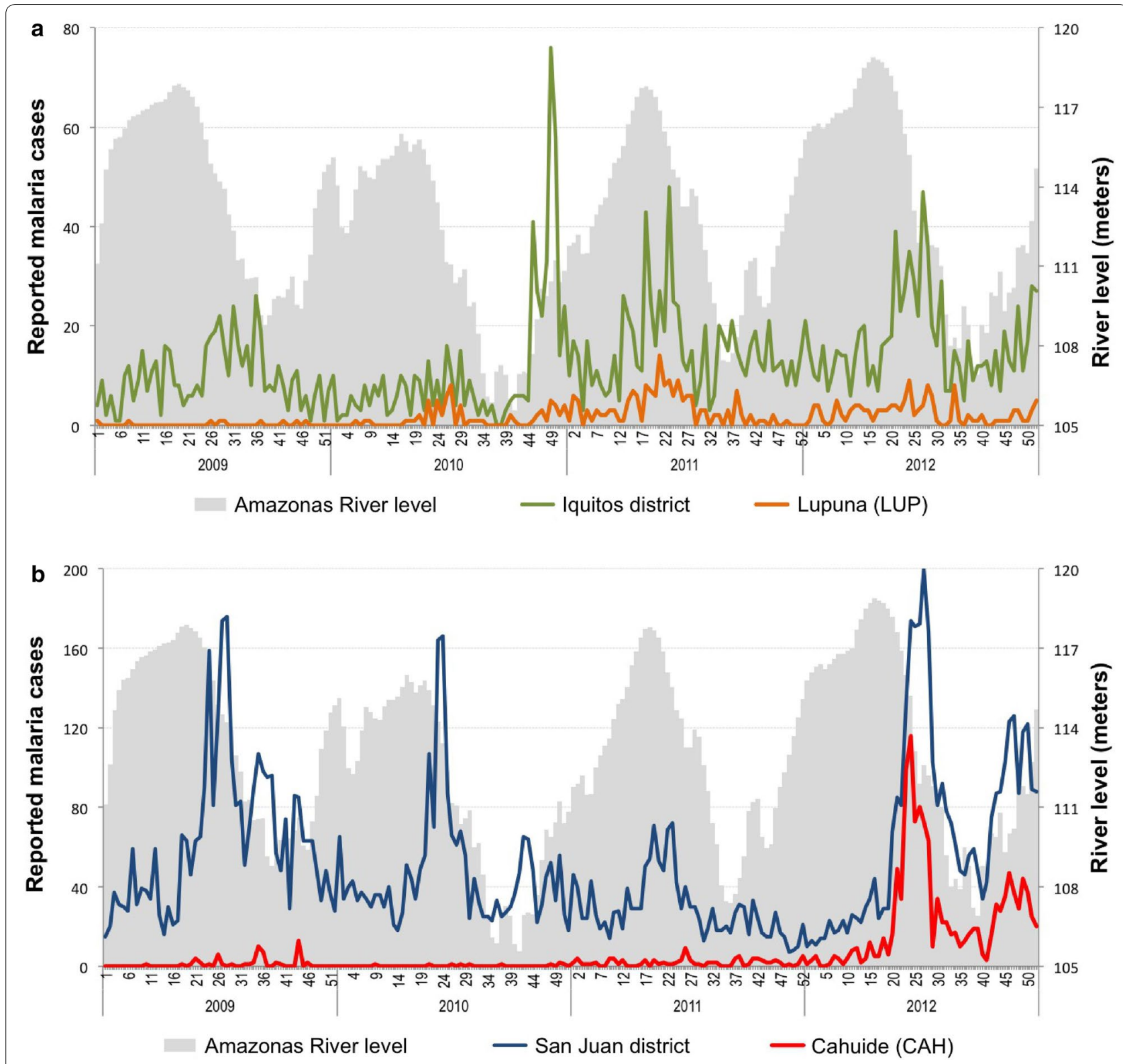

Fig. 4 Weekly reported malaria cases in Lupuna (a) and Cahuide (b), and in their respective districts, Iquitos and San Juan (2009-2012)

infection rate of collected mosquitoes (1.47\%) which indicated onward malaria transmission in the area [28], and the potential new increase of cases if ecological conditions were favourable. This is exactly what happened in November-December 2012 [13] following the early onset of heavy rains generating an abrupt height increase of level rivers since October 2012, and consequently damaging and flooding to villages located along the Amazonas River and its tributaries [9].

As previously described elsewhere in the Peruvian Amazon [16-21], the findings presented here from both LUP and CAH consistently demonstrated that a large majority of malaria infections-by both $P$. vivax and $P$. falciparum-were asymptomatic (64-85\%) and submicroscopic (75-77\%), despite differences in malaria prevalence and variations in malaria transmission over time. A limitation of such cross-sectional surveys is that they might not correctly estimate the proportion of infections that later might become symptomatic or have higher parasite density levels (as detectable by LM) [24, 34]. Few longitudinal studies in Amazonia, in particular Peru and Brazil, have provided data regarding such evolution [20, 22]. A 6-month cohort study in peri-Iquitos villages combining PCD, ACD and weekly monitoring of symptoms 
found that an important proportion of malaria infections which were asymptomatic at the time of detection (either by LM or PCR), developed malaria symptoms (reported and/or measured fever) after 1 week of follow-up, resulting in only $35-40 \%$ of asymptomatic infections among all confirmed cases in study villages [20,34]. Another study conducted in western Brazilian Amazonia in 2004-2005 [22], including cross-sectional surveys, PCD and ACD over a 14-month period, found that among 93 asymptomatic infections confirmed by PCR during surveys, only 10 (10.7\%) developed symptoms consistent with malarial disease over the subsequent 2 months of follow-up. Large prospective population cohorts with long and rigorous follow-up, as those recently implemented by the Amazonian ICEMR [26, 27], offer the opportunity to better delineate clinical and parasitological evolution of extant and/or newly acquired infections that were only detected by PCR. Population-based longitudinal study design is required to measure accurately the natural history of true and persistent asymptomatic and sub-microscopic carriers, and assess their contribution in maintaining malaria transmission in the Amazon region.

Considering the site-specific socio-demographics, household characteristics and ecological conditions in LUP and CAH, risk factor and spatial analyses of malaria infections were performed separately for each site. The low number of infections in LUP detected during the survey in low transmission season would primarily explain the difficulty in identifying malaria risk factors and spatial clusters of high transmission in the site for both $P$. vivax and P. falciparum. Household overcrowding, the only factor found to be significantly associated with $P$. falciparum infection in LUP, has also been reported in several studies conducted in areas where transmission is exclusively due to $P$. falciparum, or co-endemic with $P$. vivax $[35,36]$. The effect of household overcrowding on malaria risk may be explained by the increase in human-released chemoattractants for mosquitoes in reduced spaces [37], leading to higher human-vector contact rates. Despite the lack of association between $P$. falciparum infection and other proxy variables for socio-economic status in LUP, it is important to note that overcrowding can also reflect poor economic household conditions. The complex association between poverty and malaria is well known, which likely operates in both directions [38, 39]: poor households are less able to afford prevention and control measures and the higher burden of malaria may push these same individuals deeper into poverty.

Regardless of how the relationship of species-specific malaria with potential risk factors in $\mathrm{CAH}$ might be explained, it must be considered that our parasitological baseline survey probably captured the incipient onset of a second local outbreak of $P$. vivax and $P$. falciparum malaria. This outbreak likely included both: parasite carriers that remained despite the response to a first severe outbreak occurred between May and August 2012, and new infections by either similar or different parasite populations than those of the first outbreak. The increased risk for $P$. vivax in males and individuals aged $>15$ years together with the confirmed infection of mosquitoes in the site [28] suggests that transmission during the second outbreak may have been primarily determined by new infections (mostly asymptomatic infections with low parasitaemia) rather than by hypnozoite-triggered relapses. This explanation is further supported by entomological findings in the same site indicating that An. darlingi mosquitoes bite mainly outdoors [28], and by other studies in the Peruvian Amazon suggesting that the higher malaria risk of adult males is associated with increased humanvector contact rates following outdoor-and forest-related occupational activities (even though the latter activities were not resulted directly associated with the infection in the present study) $[14,40]$.

The differences in malaria risk between species with respect to the availability of electricity at household can be explained by the different connotations that this public service can have. While the lack of electricity may reflect poor socio-economic status associated with increased $P$. vivax infections and consequently suggest that transmission is not entirely outdoors; the electricity availability as risk factor for $P$. falciparum may be related with an increase of evening outdoor activities (e.g., watching television, chatting, resting, etc.) of household members [41]. On the other hand, the development of host immunity with the intensity of exposure to $P$. falciparum species in $\mathrm{CAH}$ (site that reports $P$. falciparum cases every year) may explain the significant relationship of $P$. falciparum infections with younger age groups [42-44], as well as, the finding that all $P$. falciparum infections had low parasite densities non-detectable by LM [16]. The results presented here from $\mathrm{CAH}$ differ from previous reports showing that prevalence and/or incidence of $P$. vivax decreased significantly faster with age than that of $P$. falciparum, suggesting that acquiring clinical immunity is different species-specific, as has been seen in other co-endemic countries such as Papua New Guinea [45], Thailand [46], Vanuatu [47], Ethiopia [48], and Brazil $[42,49]$. The data presented here regarding $\mathrm{LM}-, \mathrm{PCR}+$ malaria infection do need to be interpreted with caution, considering the limitation of cross-sectional malaria epidemiology studies because risk for transmission is highly dynamic and multifactorial. The longitudinal cohort data from both sites, once available, will allow for more precise understanding of the complex risk factors for incident malaria infection. The rich data sets will allow for more sophisticated analysis, for example, using complex 
mixed-effects regression models to account for repeated measures, clustering within household/village, and hierarchical levels of risk factors. Further, the identification and characterization of parasite populations will provide insights into complex malaria transmission dynamics in diverse scenarios, for example those characterized by changing seasonal endemic and/or epidemic transmission due to climate change, or those influenced by human mobility patterns due to social policies.

The high heterogeneity in malaria transmission in the Peruvian Amazon creates opportunities for targeted interventions [14]. However the identification of hotspots of malaria transmission and their characterization are not always straightforward. In our study, SaTScan analysis detected clusters with the highest malaria prevalence for both $P$. vivax and P. falciparum only in the CAH site. Since the cluster located on the south of CAH for $P$. vivax was found to be associated with an increased presence of male individuals, age groups older than 15 years and the lack of electricity at households, an adjusted spatial analysis for these covariates was performed resulting in the disappearance of the cluster. The observation indicating that the aggregation of $P$. vivax infections was mainly determined by the aggregation of groups with high-risk than by specific ecological conditions within the site has also been reported in other villages of the Peruvian Amazon [14]. Local mosquito and human mobility patterns may explain the absence of clustering of specific environmental factors along the Iquitos-Nauta road. Indeed, the presence of several breeding and resting sites near households along the road which enlarge after rains or floods from Itaya River could result into a wider dispersal of $A n$. darlingi, and the high mobility of infected individuals through the unique and highly accessible road could further increase the dispersal of parasites. Conversely, the cluster for $P$. falciparum remained in the closest area to the river even after being adjusted for age and electricity availability (variables associated with $P$. falciparum infection). Its highest prevalence may be explained by the unprecedented floods from Itaya River in 2012 resulting in large and multiple breeding sites in the area, but also by the presence of a fluvial port to which individuals (resident and non-residents) arrive after being exposed to malaria due to travel-related economical activities in other endemic riverine villages.

\section{Conclusions}

Parasitological measures (by LM and PCR), and individual and household characteristics collected during the baseline survey of a 3-year population-based malaria cohort study in the Amazonian Lupuna and Cahuide villages, together with contextual data obtained from malaria surveillance systems and health facilities, allowed for a good characterization of their population and malaria transmission patterns. On a population basis in both sites, low parasite rates were observed, with findings that asymptomatic and sub-patent infections predominated, compared to symptomatic and patent infections. However, the site-specific analysis of malaria prevalence and reported incidence showed substantial heterogeneity in malaria transmission at the micro-geographical level and over time, likely influenced by the site-specific sociodemographics, household characteristics, and ecological conditions in the villages. Riverine and road construction/deforestation contexts must be taken into account in order to carry out effective anti-malaria control and elimination efforts.

\section{Additional files}

Additional file 1: Table S1. Baseline socio-demographic characteristics of study participants by villages. Table S2. Baseline household characteristics of study participants by villages

Additional file 2: Figure S1. Weekly reported malaria cases in Cahuide (B) in 2012, and main control interventions implemented. (1) Mass screening and treatment (MS\&T) and indoor spraying with residual insecticide with $>90 \%$ of household coverage; $(2,3,5,6,7)$ MS\&T; (4) distribution of LLINs.

\section{Authors' contributions}

$J V, A L C$ and DG conceived and designed the study. MG and RC supervised the fieldwork. DG, RR and PM supervised the laboratory assays. ARA, MG, GCE and CP contributed to the data management and the consolidation of the fieldwork and laboratory data. ARA conducted the analysis, prepared figures and tables, interpreted the results, and wrote the first draft of the paper. JV, ALC and DG contributed to the result interpretation and writing of the paper. All authors read and approved the final manuscript.

\section{Author details}

${ }^{1}$ Instituto de Medicina Tropical Alexander von Humboldt, Universidad Peruana Cayetano Heredia, Lima 31, Peru. ${ }^{2}$ Research Institute of Health and Society (IRSS), Université Catholique de Louvain, 1200 Brussels, Belgium. ${ }^{3}$ Laboratorio ICEMR-Amazonia, Laboratorios de Investigación y Desarrollo, Facultad de Ciencias y Filosofia, Universidad Peruana Cayetano Heredia, Lima 31, Peru. ${ }^{4}$ Departamento de Ciencias Celulares y Moleculares, Facultad de Ciencias y Filosofia, Universidad Peruana Cayetano Heredia, Lima 31, Peru. ${ }^{5}$ Facultad de Salud Pública y Administración, Universidad Peruana Cayetano Heredia, Lima 31, Peru. ${ }^{6}$ Division of Infectious Diseases, Department of Medicine, University of California San Diego School of Medicine, 9500 Gilman Drive MC0760, Biomedical Research Facility-2, Room 4A16, La Jolla, California, CA 92093, USA.

\section{Acknowledgements}

We thank all residents and local authorities from the Loreto villages of Cahuide and Lupuna for their enthusiastic participation in the study, as well as all field workers for their dedication during the fieldwork. This study was funded by cooperative agreement U19AI089681 from the United States Public Health Service, NIH/NIAID, funded as the Amazonian International Center of Excellence in Malaria Research.

\section{Competing interests}

The authors declare that they have no competing interests.

\section{Publisher's Note}

Springer Nature remains neutral with regard to jurisdictional claims in published maps and institutional affiliations. 
Received: 6 April 2017 Accepted: 28 July 2017

Published online: 04 August 2017

\section{References}

1. Nájera JA, González-Silva M, Alonso PL. Some lessons for the future from the Global Malaria Eradication Programme (1955-1969). PLoS Med. 2011:8:e1000412.

2. Rosas-Aguirre A, Gamboa D, Manrique P, Conn JE, Moreno M, Lescano AG, et al. Epidemiology of Plasmodium vivax malaria in Peru. Am J Trop Med Hyg. 2016;95:133-44.

3. Griffing SM, Gamboa D, Udhayakumar V. The history of 20th century malaria control in Peru. Malar J. 2013;12:303.

4. Cueto M. El regreso de las epidemias: salud y sociedad en el Perú del siglo XX. IEP; 1997

5. Williams HA, Vincent-Mark A, Herrera Y, Chang OJ. A retrospective analysis of the change in anti-malarial treatment policy: Peru. Malar J. 2009;8:85.

6. Ruebush TK, Neyra D, Cabezas C. Modifying national malaria treatment policies in Peru. J Public Health Policy. 2004;25:328-45.

7. Guarda JA, Asayag CR, Witzig R. Malaria reemergence in the Peruvian Amazon region. Emerg Infect Dis. 1999;5:209-15.

8. Vittor AY, Gilman RH, Tielsch J, Glass G, Shields T, Lozano WS, et al. The effect of deforestation on the human-biting rate of Anopheles darlingi, the primary vector of falciparum malaria in the Peruvian Amazon. Am J Trop Med Hyg. 2006;74:3-11.

9. Soto-Calle V, Rosas-Aguirre A, Llanos-Cuentas A, Abatih E, DeDeken R, Rodriguez $\mathrm{H}$, et al. Spatio-temporal analysis of malaria incidence in the Peruvian Amazon Region between 2002 and 2013. Sci Rep. 2017;7:40350.

10. Flores W, Chang J, Barillas E. Rapid assessment of the performance of malaria control strategies implemented by countries in the Amazon subregion using adequacy criteria: case study. Malar J. 2011;10:379.

11. Rosas-Aguirre A, Guzmán-Guzmán M, Moreno-Gutierrez D, RodriguezFerrucci H, Vargas-Pacherrez D, Acuña-González Y. Long-lasting insecticide-treated bednet ownership, retention and usage one year after their distribution in Loreto, Peru. Rev Peru Med Exp Salud Pública. 2011;28:228-36 (in Spanish)

12. Rosas-Aguirre Á, Gamboa D, Rodriguez H, Llanos-Zavalaga F, Aguirre K, Llanos-Cuentas A. Use of standardized blood smear slide sets for competency assessment in the malaria microscopic diagnosis in the Peruvian Amazon. Rev Peru Med Exp Salud Pública. 2010;27:540-7 (in Spanish).

13. Ministerio de Salud del Perú. Tendencia y situación de las enfermedades sujetas a vigilancia epidemiológica: malaria. Bol Epidemiol. 2015:24:975-86

14. Rosas-Aguirre A, Speybroeck N, Llanos-Cuentas A, Rosanas-Urgell A Carrasco-Escobar G, Rodriguez H, et al. Hotspots of malaria transmission in the Peruvian Amazon: rapid assessment through a parasitological and serological survey. PLoS ONE. 2015;10:e0137458.

15. Ministerio de Salud del Perú. Norma técnica para la atención de la malaria y malaria severa en el Perú. NTS Nro. 054-MINSA/DGSP-V.01, modificada en Febrero 2015. MINSA; 2015.

16. Okell LC, Ghani AC, Lyons E, Drakeley CJ. Submicroscopic infection in Plasmodium falciparum-endemic populations: a systematic review and meta-analysis. J Infect Dis. 2009;200:1509-17.

17. Bousema T, Okell L, Felger I, Drakeley C. Asymptomatic malaria infections: detectability, transmissibility and public health relevance. Nat Rev Microbiol. 2014;12:833-40.

18. Lindblade KA, Steinhardt L, Samuels A, Kachur SP, Slutsker L. The silent threat: asymptomatic parasitaemia and malaria transmission. Expert Rev Anti Infect Ther. 2013;11:623-39.

19. Parekh FK, Hernandez JN, Krogstad DJ, Casapia WM, Branch OH. Prevalence and risk of Plasmodium falciparum and P. vivax malaria among pregnant women living in the hypoendemic communities of the Peruvian Amazon. Am J Trop Med Hyg. 2007:77:451-7.

20. Branch O, Casapia WM, Gamboa DV, Hernandez JN, Alava FF, Roncal N, et al. Clustered local transmission and asymptomatic Plasmodium falciparum and Plasmodium vivax malaria infections in a recently emerged, hypoendemic Peruvian Amazon community. Malar J. 2005:4:27.
21. Roshanravan B, Kari E, Gilman RH, Cabrera L, Lee E, Metcalfe J, et al. Endemic malaria in the Peruvian Amazon Region of lquitos. Am J Trop Med Hyg. 2003;69:45-52.

22. da Silva-Nunes M, Moreno M, Conn JE, Gamboa D, Abeles S, Vinetz JM et al. Amazonian malaria: asymptomatic human reservoirs, diagnostic challenges, environmentally-driven changes in mosquito vector populations, and the mandate for sustainable control strategies. Acta Trop. 2012;121:281-91.

23. Vinetz JM, Gilman RH. Asymptomatic Plasmodium parasitemia and the ecology of malaria transmission. Am J Trop Med Hyg. 2002;66:639-40.

24. Coura JR, Suárez-Mutis M, Ladeia-Andrade S. A new challenge for malaria control in Brazil: asymptomatic Plasmodium infection—a review. Mem Inst Oswaldo Cruz. 2006;101:229-37.

25. Barbosa S, Gozze AB, Lima NF, Batista CL, da Silva Bastos M, Nicolete VC, et al. Epidemiology of disappearing Plasmodium vivax malaria: a case study in rural Amazonia. PLoS Negl Trop Dis. 2014;8:e3109.

26. Rao MR. International centers of excellence for malaria research. Am J Trop Med Hyg. 2015;93:1-4.

27. Moss WJ, Dorsey G, Mueller I, Laufer MK, Krogstad DJ, Vinetz JM, et al. Malaria epidemiology and control within the international centers of excellence for malaria research. Am J Trop Med Hyg. 2015;93:5-15.

28. Moreno M, Saavedra MP, Bickersmith SA, Lainhart W, Tong C, Alava F, et al. Implications for changes in Anopheles darlingi biting behaviour in three communities in the peri-lquitos region of Amazonian Peru. Malar J. 2015;14:290.

29. Ministerio de Salud del Perú. Norma técnica de salud para el control de calidad del diagnóstico microscópico de malaria. Lima: MINSA; 2010.

30. Mangold KA, Manson RU, Koay ESC, Stephens L, Regner M, Thomson RB, et al. Real-time PCR for detection and identification of Plasmodium spp. J Clin Microbiol. 2005;43:2435-40.

31. Kulldorff M. SaTScan — software for the spatial, temporal, and spacetime scan statistics. Boston: Harvard Medical School and Harvard Pilgrim Health Care; 2010

32. Tusting LS, Bousema T, Smith DL, Drakeley C. Measuring changes in Plasmodium falciparum transmission: precision, accuracy and costs of metrics. Adv Parasitol. 2014:84:151-208.

33. Elissa N, Migot-Nabias F, Luty A, Renaut A, Touré F, Vaillant M, et al. Relationship between entomological inoculation rate, Plasmodium falciparum prevalence rate, and incidence of malaria attack in rural Gabon. Acta Trop. 2003:85:355-61.

34. Rosas-Aguirre A, Erhart A, Llanos-Cuentas A, Branch O, Berkvens D, Abatih $E$, et al. Modelling the potential of focal screening and treatment as elimination strategy for Plasmodium falciparum malaria in the Peruvian Amazon Region. Parasites Vectors. 2015:8:261.

35. Ernst KC, Adoka SO, Kowuor DO, Wilson ML, John CC. Malaria hotspot areas in a highland Kenya site are consistent in epidemic and non-epidemic years and are associated with ecological factors. Malar J. 2006;5:78.

36. Ricci F. Social implications of malaria and their relationships with poverty. Mediterr J Hematol Infect Dis. 2012;4:2012048.

37. Zwiebel LJ, Takken W. Olfactory regulation of mosquito-host interactions. Insect Biochem Mol Biol. 2004:34:645-52.

38. Rosas-Aguirre A, Ponce OJ, Carrasco-Escobar G, Speybroeck N, ContrerasMancilla J, Gamboa D, et al. Plasmodium vivax malaria at households: spatial clustering and risk factors in a low endemicity urban area of the northwestern Peruvian coast. Malar J. 2015:14:176.

39. Teklehaimanot A, Mejia P. Malaria and poverty. Ann NY Acad Sci. 2008:1136:32-7.

40. Chuquiyauri R, Paredes M, Peñataro P, Torres S, Marin S, Tenorio A, et al. Socio-demographics and the development of malaria elimination strategies in the low transmission setting. Acta Trop. 2012;121:292-302.

41. Gryseels C, Durnez L, Gerrets R, Uk S, Suon S, Set S, et al. Re-imagining malaria: heterogeneity of human and mosquito behaviour in relation to residual malaria transmission in Cambodia. Malar J. 2015;14:165

42. Ladeia-Andrade S, Ferreira MU, de Carvalho ME, Curado I, Coura JR. Age-dependent acquisition of protective immunity to malaria in riverine populations of the Amazon Basin of Brazil. Am J Trop Med Hyg. 2009;80:452-9.

43. Clark EH, Silva CJ, Weiss GE, Li S, Padilla C, Crompton PD, et al. Plasmodium falciparum malaria in the Peruvian Amazon, a region of low transmission, is associated with immunologic memory. Infect Immun. 2012:80:1583-92. 
44. Doolan DL, Dobaño C, Baird JK. Acquired immunity to malaria. Clin Microbiol Rev. 2009;22:13-36.

45. Lin E, Kiniboro B, Gray L, Dobbie S, Robinson L, Laumaea A, et al. Differential patterns of infection and disease with P. falciparum and P. vivax in young Papua New Guinean children. PLoS ONE. 2010;5:e9047.

46. Phimpraphi W, Paul RE, Yimsamran S, Puangsa-art S, Thanyavanich N, Maneeboonyang $\mathrm{W}$, et al. Longitudinal study of Plasmodium falciparum and Plasmodium vivax in a Karen population in Thailand. Malar J. 2008;7:99.

47. Maitland K, Williams TN, Bennett S, Newbold Cl, Peto TE, Viji J, et al. The interaction between Plasmodium falciparum and P. vivax in children on Espiritu Santo island, Vanuatu. Trans R Soc Trop Med Hyg. 1996;90:614-20.
48. Seyoum D, Kifle YG, Rondeau V, Yewhalaw D, Duchateau L, Rosas-Aguirre A, et al. Identification of different malaria patterns due to Plasmodium falciparum and Plasmodium vivax in Ethiopian children: a prospective cohort study. Malar J. 2016;15:208.

49. da Silva-Nunes M, Codeço CT, Malafronte RS, da Silva NS, Juncansen C, Muniz PT, et al. Malaria on the Amazonian frontier: transmission dynamics, risk factors, spatial distribution, and prospects for control. Am J Trop Med Hyg. 2008;79:624-35.

\section{Submit your next manuscript to BioMed Central and we will help you at every step:}

- We accept pre-submission inquiries

- Our selector tool helps you to find the most relevant journal

- We provide round the clock customer support

- Convenient online submission

- Thorough peer review

- Inclusion in PubMed and all major indexing services

- Maximum visibility for your research

Submit your manuscript at www.biomedcentral.com/submit 